\title{
Improved Direct Torque Control for Induction Motor with Fuzzy-PI controllers
}

\author{
Chengli Zhu, Yanzhong Wang and Liangwei Hou \\ School of Mechanical Engineering and Automation \\ Beihang University \\ Beijing, China \\ chenglizhu888@163.com
}

\begin{abstract}
This paper presents an improved direct torque control scheme with space vector modulation techniques (DTC-SVM) for induction motors to eliminate the disadvantages of the traditional DTC-SVM scheme at low speed, speed step changing and torque step changing. Unlike the traditional DTC-SVM using PI controllers in the speed, flux and torque control loops, the improved DTC-SVM scheme uses Fuzzy-PI controllers in these control loops. Simulations with the deferent operating conditions for the presented DTC-SVM scheme and conventional DTC-SVM scheme are carried out in the Matlab/Simulink platform. According to the simulation results, the improved DTC-SVM scheme with Fuzzy-PI controllers produce better performances in terms of response, efficient of flux and speed regulations with dynamic load.
\end{abstract}

Keywords- Induction Motor; Direct Torque Control; DTCSVM; Fuzzy Logic Controller; PI Controller

\section{INTRODUCTION}

Previously, DC motors are normally used in the systems which requires high performances of precise and wide range speed control, Since they have the advantages of good starting-up, wide speed range, smooth speed regulation, and easy to be controlled. Therefore, the DC motors have the mechanical commutator and brush which make the maintenance of them relatively difficult. They still have the disadvantages of big size, high cost and short lifetime. On the contrary, AC motors, especially the squirrel cage induction motors, have the characteristics of simple structure, good reliability, and low costs. Additionally, they can be used in harsh environments. With the progress of the power electronics, microelectronics and digital control technology, as well as the development of the control theory, AC motors have the comparable speed regulation performance like DC motors. Nowadays, variable speed AC motors have been widely used in the industry, mining, agriculture and transportation fields [1-3].

AC motor is a complex, nonlinear, multivariable, strong coupling and parameter time-varying system. The precise control of speed and electromagnetic is the main problem of the induction motor application system. So, the effective control of the induction motor is always an active research area in the world [4] Several scalar based control and vector based control strategies for induction motor have been proposed in the past decades. Scalar based control methods, such as the constant voltage/frequency control method, are easily to be implemented, but the performance of this kind of control method is not good enough [5]. Unlike scalar based control methods, the vector based control methods allow the control of amplitude of voltage and frequency simultaneously. And they also provide instantaneous position of the current, voltage and flux vectors. The dynamic performance of the induction motors is improved significantly with the use of vector based control method [6]. However, the induction motor has a nonlinear structure and there is a coupling between flux and the produced electromagnetic torque in the motor [7]. In order to solve those problems, several methods for decoupling torque and flux, such as: Field Oriented Control (FOC) [8], Feedback Linearization Control (FLC) [9], Passivity Based Control (PBC) [10] and Direct Torque Control (DTC) [11] have been proposed in the past decades.

FOC methods were investigated and discussed by many researchers and have now become an industry standard. In FOC method, Decoupling of two components of stator currents (flux and torque producing components) is achieved as DC machines to provide independent torque control. However, FOC technique is complex and difficult to be implemented, because it requires reference frame transformation and is dependent on the mechanical speed and motor parameters. In order to overcome these difficulties, DTC strategy was proposed by Takashiand Noguchi in 1980s. In the conventional DTC methods, large flux and torque ripples, as well as non-constant switching frequency of the inverter are the main problems [12]. Many attempts have been taken to overcome these limitations in the last years.

A popular solution to reduce torque ripple of the conventional DTC drive is using the space vector modulation techniques. This kind of control method is called DTC-SVM scheme [13]. Comparing with the conventional DTC system, the hysteresis controllers are replaced by the PI controllers, and the switching table is replaced by the space vector modulator. Generally, the error vector in flux and torque can be compensated, and the DTC-SVM can operate at a constant switching frequency. This helps to reduce torque and flux ripples [14]. The main problem of the traditional DTC scheme is the poor performance at low speed where stator flux estimation becomes strongly dependent on the stator resistance, as well as the poor performance at torque step changing. In order to improve the DTC-SVM performance, it is needed an advance control technique, such as fuzzy logic controller [15].

In recent years, fuzzy systems are applied in wide range of academic and industrial fields such as modeling and control, signal possessing, medicine, etc. [16]. Fuzzy 
logic controller (FLC) does not need complex mathematical algorithms, which is based on the "IF THEN" linguistic rules. It is universal approximation and can be used to uniformly-approximate nonlinear continuous functions to arbitrary accuracy [17]. ChangMing Liaw and Jin-Biau Wang [18] developed a fuzzy controller for speed control feedback loop to obtain good dynamic rotor speed response. Sousa G C D, Bose B K, et al. [19] used fuzzy logic controller to improve the induction motor speed control system. Hossain A, et al. [20] proposed an integrated control model using an adaptive neuro fuzzy inference system for wind turbine power management strategy. They developed a fuzzy expert system with artificial neural network. Rafa S, Larabi A, Barazane L, et al. [21] implemented a real-time fuzzy vector control scheme using a digital signal processor board dSPACE 1104. However, the pure fuzzy control methods can not eliminate the steady state error of the system.

In this paper, an improved DTC-SVM scheme is proposed to improve the control performance of the DTCSVM method at low speed, speed step changing and step torque changing. In the proposed DTC-SVM scheme, the Fuzzy-PI controllers are used in the flux, torque and speed control loops. The performances of the proposed DTCSVM method are evaluated in the Matlab/Simulink platform. The simulation results show that the control performances of the proposed DTC-SVM scheme are improved compared with the traditional DTC-SVM method.

\section{INDUCTION MOTOR MATHEMATICAL MODEL}

In order to make it convenient to model three phase induction motor by mathematical equations, it is necessary to make the following assumptions. The motor is a symmetrical three phase motor and the rotor and stator windings are replaced by a concentrated coil. Only the fundamental harmonic is considered and all other losses except core loss and friction loss are ignored. The coil resistance and reactance are considered invariant. Based on these assumptions, the three-phase induction motor mathematical model can be expressed by the following equations.

The stator voltage vector equation in synchronous reference frame can be written as:

$$
U_{s}=R_{s} I_{s}+\frac{d \psi_{s}}{d t}
$$

Where: $U_{s}$ is stator voltage space vector, $I_{s}$ is stator current space vector, $R_{s}$ is the resistant of the stator coil, and $\psi_{s}$ is the stator flux linkage space vector.

The Stator flux vector $\psi_{s}$ equations can be written as:

$$
\psi_{s}=L_{s} I_{s}+L_{m} I_{r}
$$

Where: $L_{s}$ is the stator self-inductance, $L_{m}$ is the mutual inductance between stator and rotor, and $I_{r}$ is the rotor current.

Similarly, the rotor flux vector $\psi_{r}$ can be expressed as:

$$
\psi_{r}=L_{r} I_{r}+L_{m} I_{s}
$$

Where: $L_{r}$ is the rotor self-inductance. The relationship among stator current, stator flux and rotor flux can be written as:

$$
I_{s}=\frac{\psi_{s}}{L_{s}}+\frac{\psi_{s}-\psi_{r}}{L_{m}}
$$

The electromagnetic torque $T_{e}$ developed by the induction motor in terms of stator and rotor flux vectors can be written as:

$$
\begin{aligned}
& T_{e}=\frac{3}{2} p_{n} \frac{L_{m}}{L_{r} L_{s} \sigma}\left(\psi_{r} \otimes \psi_{s}\right) \\
& =\frac{3}{2} p_{n} \frac{L_{m}}{L_{r} L_{s} \sigma}\left|\psi_{r}\right| \cdot\left|\psi_{s}\right| \sin \left(\theta_{s}-\theta_{r}\right) \\
& =\frac{3}{2} p_{n} \frac{L_{m}}{L_{r} L_{s} \sigma}\left|\psi_{r}\right| \cdot\left|\psi_{s}\right| \sin \theta
\end{aligned}
$$

Where: $p_{n}$ is the number of pole pairs, $\theta$ is the angle between the stator and rotor flux vectors, i.e. the torque angle, and $\sigma$ is the leakage factor which is defined as:

$$
\sigma=1-\frac{L_{m}^{2}}{L_{s} L_{r}}
$$

Finally, the torque balance equation of the dynamic rotor rotation can be written by:

$$
J \frac{d \omega}{d t}=T_{e}-T_{L}-B \omega
$$

Where: $\omega$ is the angular speed of the rotor, $T_{L}$ is the load torque, $B$ is the viscous constant, and $J$ is the inertia of the induction motor.

From (5) we can see that the electromagnetic torque is cross vector product between the stator and rotor flux vectors. If the sample time is short enough, the amplitude of the stator flux is generally kept constant at the reference value. Accordingly, the rotor flux is also kept constant because it changes slower than the stator flux. The electromagnetic torque can be controlled by changing the torque angle $\theta$. And the angle $\theta$ can be easily controlled by choosing appropriate stator voltage space vector. This is the basic of DTC control method for the induction motors.

\section{STRUCTURE OF THE PROPOSED DTC-SVM SCHEME}

The block diagram of the proposed control scheme is presented in Fig. 1. The speed, torque and flux magnitudes are controlled with closed-loop way. They are regulated by the Fuzzy-PI controllers respectively.

For the purpose of illustrate Fuzzy-PI controller structure used in the improved DTC-SVM scheme, the block diagram of the speed Fuzzy-PI controller is presented in Fig. 2.

The proportional gain $K_{p}$ and integral gain $K_{i}$ of the PI controller are updated by the fuzzy inference according to the error $e$ and its change $\Delta e . K_{p}$ should be selected a larger value, and the $K_{i}$ should be selected smaller value when the error is relatively large, which can make the system have smaller overshoot and faster response. When the error is moderate, moderate $K_{p}$ and larger $K_{i}$ should be 


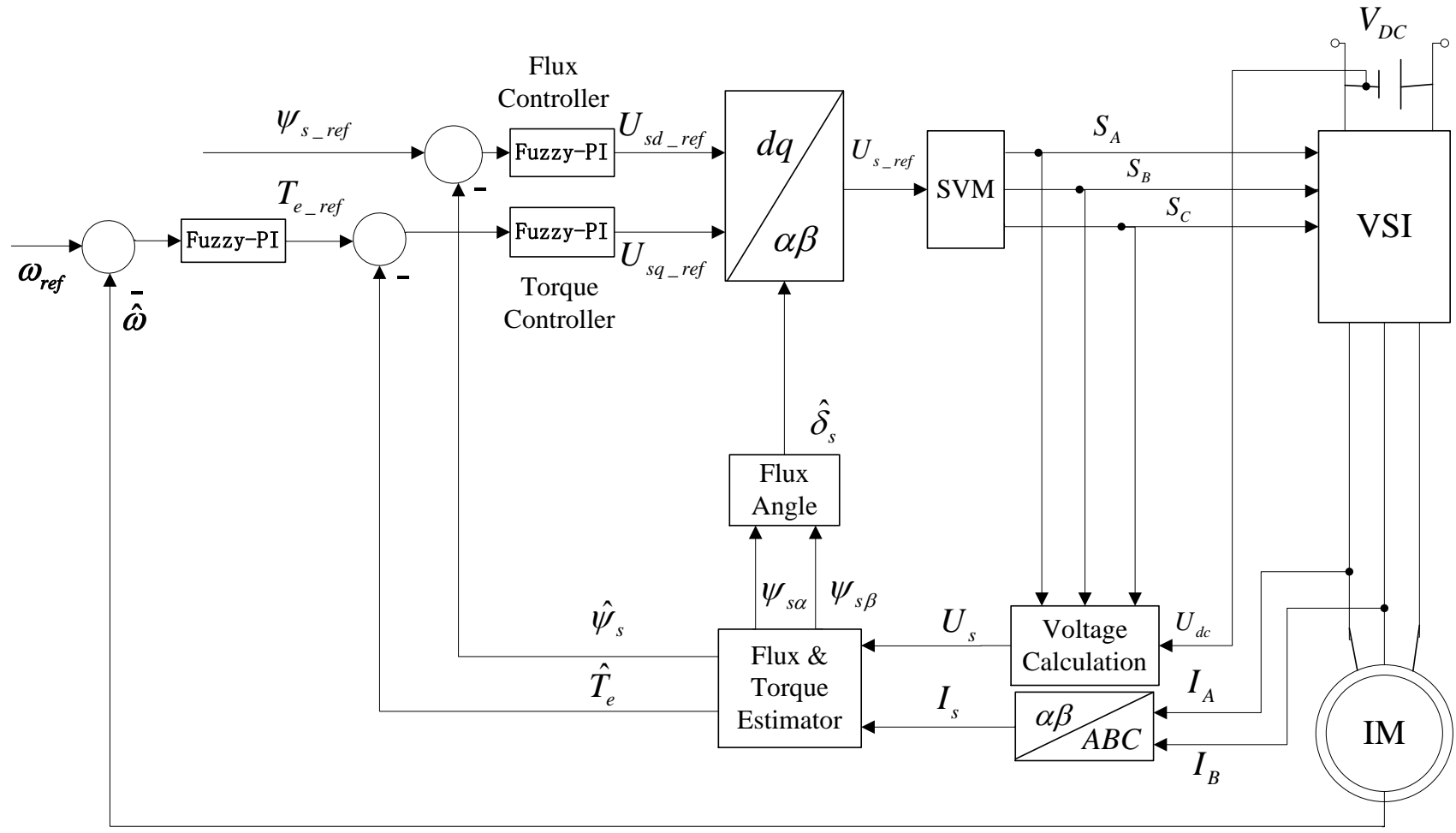

Figure 1. Block diagram of of the improved DTC scheme with Fuzzy-PI controllers

selected to quickly eliminate the static error. When the error is smaller, it should select a smaller $K_{p}$ and larger $K_{i}$ to enhance the capacity of resisting disturbance.

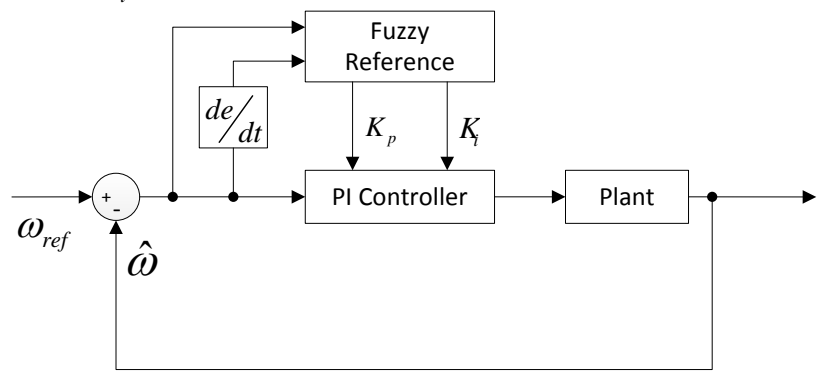

Figure 2. Block diagram of Fuzzy-PI controller

The proposed DTC-SVM schema is based on the information of flux, torque and mechanical speed. In this paper, the magnitude of the stator flux reference is considered constantly. The reference stator flux vector can be calculated by the following equation:

$$
\psi_{s_{-} r e f}=\left|\psi_{s_{-} r e f}\right| e^{j\left(\hat{\gamma}_{s s}+\Delta \delta_{\psi}\right)}
$$

Where: $\hat{\gamma}_{s s}$ is the estimated stator flux vector angle, $\Delta \delta_{\psi}$ is the angle between the reference and estimated stator flux vector. The components of the stator flux reference in the stationary coordinate system can be written as follows:

$$
\begin{aligned}
& \psi_{s_{d_{-} r e f}}=\left|\psi_{s_{-} r e f}\right| \cos \left(\hat{\gamma}_{s s}+\Delta \delta_{\psi}\right) \\
& \psi_{s_{q_{-} r e f}}=\left|\psi_{s_{-} r e f}\right| \sin \left(\hat{\gamma}_{s s}+\Delta \delta_{\psi}\right)
\end{aligned}
$$

The stator flux estimation and reference can be written as:

$$
\hat{\psi}_{s}=\int\left(U_{s}-R_{s} I_{s}\right) d t
$$

With the stator flux components $\hat{\psi}_{s d}$ and $\hat{\psi}_{s q}$, the angle of the stator flux can be obtained by:

$$
\hat{\gamma}_{s s}=\tan ^{-1}\left(\frac{\hat{\psi}_{s q}}{\hat{\psi}_{s d}}\right)
$$

The estimated torque $\hat{T}_{e}$ of the motor in terms of the stator flux and the stator current in $\alpha \beta$ stationary reference frame can be written as:

$\hat{T}_{e}=p_{b} \frac{m_{s}}{2} \operatorname{Im}\left(\hat{\psi}_{s}^{*} I_{s}\right)=p_{b} \frac{m_{s}}{2}\left(\hat{\psi}_{s \alpha} I_{s \beta}-\hat{\psi}_{s \beta} I_{s \alpha}\right)$

It is clear that the estimated electromagnetic torque is depended on the measurement accuracy of the current and flux estimation.

From Fig 1., it can be seen that the inputs of the voltage calculation block are the DC power voltage and the inverter switch states $\left(S_{A}, S_{B}, S_{C}\right)$. The stator voltage vector can be expressed as:

$\hat{U}_{s}=\frac{2}{3}\left[\left(S_{A}-\frac{S_{A}+S_{B}}{2}\right)+j \frac{\sqrt{3}}{2}\left(S_{B}-S_{C}\right)\right] U_{D C}$

In this method, the speed Fuzzy-PI controller is used to optimize the reference torque $\left(T_{e_{-} r e f}\right)$ of the motor from the error between reference speed and the rotor speed $\left(\omega_{\text {ref }}, \hat{\omega}\right)$ respectively. The error between the estimated stator flux and reference stator flux is the input signal of the Fuzzy-PI controller. It is used to calculate the stator voltage component. Similarly, the estimated electromagnetic torque is compared to the reference electromagnetic torque to generate the error signal for the torque Fuzzy-PI controller. And the output of the torque PI 
controller is the stator voltage vector component. The reference stator voltage vector components $U_{\text {sd_ref }}$ and $U_{s q_{-} r e f}$ are transformed into stationary reference frame ( $\alpha \beta$ frame) by the coordinate transformation functions. Then, the DC voltage commands are forwarded to the SVM block which can perform the space vector modulation. After that, appropriate space voltage vector can be generated by the three-phase inverter with the inverter switch PWM signals $\left(S_{A}, S_{B}, S_{C}\right)$ calculated by the SVM block.

\section{Simulation AND Results}

In order to verify the performance of the proposed improved DTC-SVM strategy, the simulation model is built and simulated in Matlab/Simulink platform. The switching frequency of PWM inverter is $5 \mathrm{kHz}$. The parameters of the induction motor are given in the table1. And the stator flux reference considered was $0.8 \mathrm{~Wb}$ which is the rated stator flux.

TABLE I. INDUCTION MOTOR PARAMETERS

\begin{tabular}{|l|c|c|}
\hline 3-Phase & $147 \mathrm{kw}$ & $\mathrm{R}_{\mathrm{s}}=0.015 \Omega$ \\
\hline $60 \mathrm{~Hz}$ & $4-\mathrm{Poles}$ & $\mathrm{R}_{\mathrm{r}}=0.009 \Omega$ \\
\hline $460 \mathrm{~V}$ & $\mathrm{~L}_{\mathrm{m}}=0.010 \mathrm{H}$ & $\mathrm{L}_{\mathrm{s}}=0.003 \mathrm{H}$ \\
\hline $\mathrm{N}_{\mathrm{r}}=1800 \mathrm{rpm}$ & Friction $=0.08$ & $\mathrm{~L}_{\mathrm{r}}=0.003 \mathrm{H}$ \\
\hline $\mathrm{J}=3.1 \mathrm{~kg} / \mathrm{m}^{2}$ & & \\
\hline
\end{tabular}

For the purpose of investigating the effectiveness of the improved DTC-SVM system and checking the closed-loop stability of the whole system, several tests were performed with different operating conditions, such as starting up and step changing in the load torque. In the first case, the induction motor is under the control of DTC-SVM method with PI controllers. The reference speed is set at 500rpm at starting up. And after 0.8 seconds, a load torque of 500 N.m is applied on the induction machine. In the second case, the induction motor is under the control of DTCSVM method with Fuzzy-PI controllers with the same operating conditions as the first case. The following figures illustrate the comparisons of the speed responses, stator currents and the electromagnetic torques of the two cases.

The speed response comparison is presented in Fig. 3 . It can be seen that the speed of the induction motor under the control of DTC-SVM method with Fuzzy-PI controllers is faster, which tends to reference speed with respect to that of the DTC-SVM method with PI controllers. And the speed change of the induction motor is not significantly in the case of DTC-SVM with Fuzzy-PI controllers when the load torque has a step change. But in the case of DTC-SVM with PI controllers, the speed change is significantly, and it needs 0.2 second to come back to the reference speed after the step change of the load torque.

The electromagnetic torque curves of the induction motor under the control of DTC-SVM method with PI regulators and the DTC-SVM method with Fuzzy-PI regulators are illustrated in Fig. 4 and Fig. 5 respectively.
In Fig. 4, the electromagnetic torque curve has an upward or downward slope when the load torque of the induction motor has a step change. In Fig. 5, the curve of the electromagnetic torque has a slight oscillation at the moment of load torque mutation. But, it quickly becomes a horizontal line (in about 0.04 second).

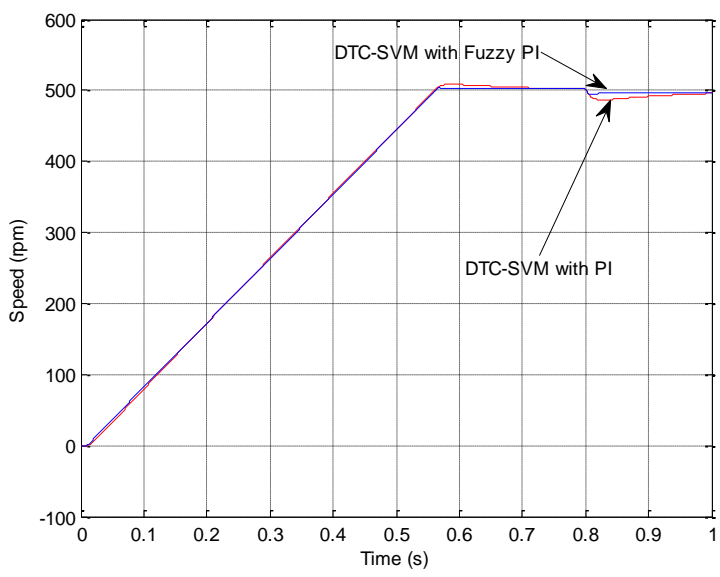

Figure 3. Speed response comparison

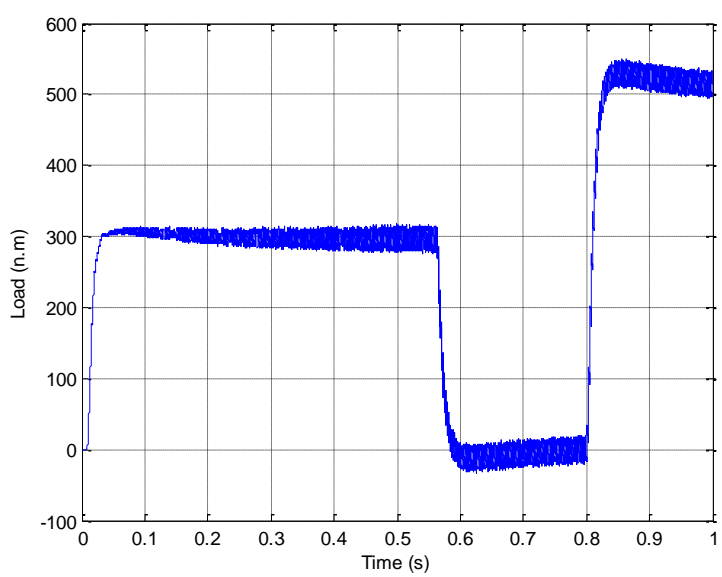

Figure 4. Electromagnetic torque curve of the traditional DTC-SVM shceme

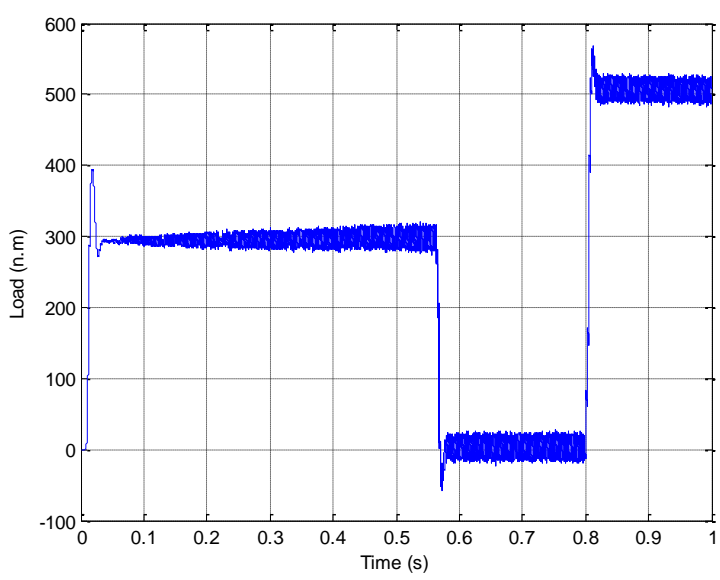

Figure 5. Electromagnetic torque curve of the improved DTC-SVM scheme 


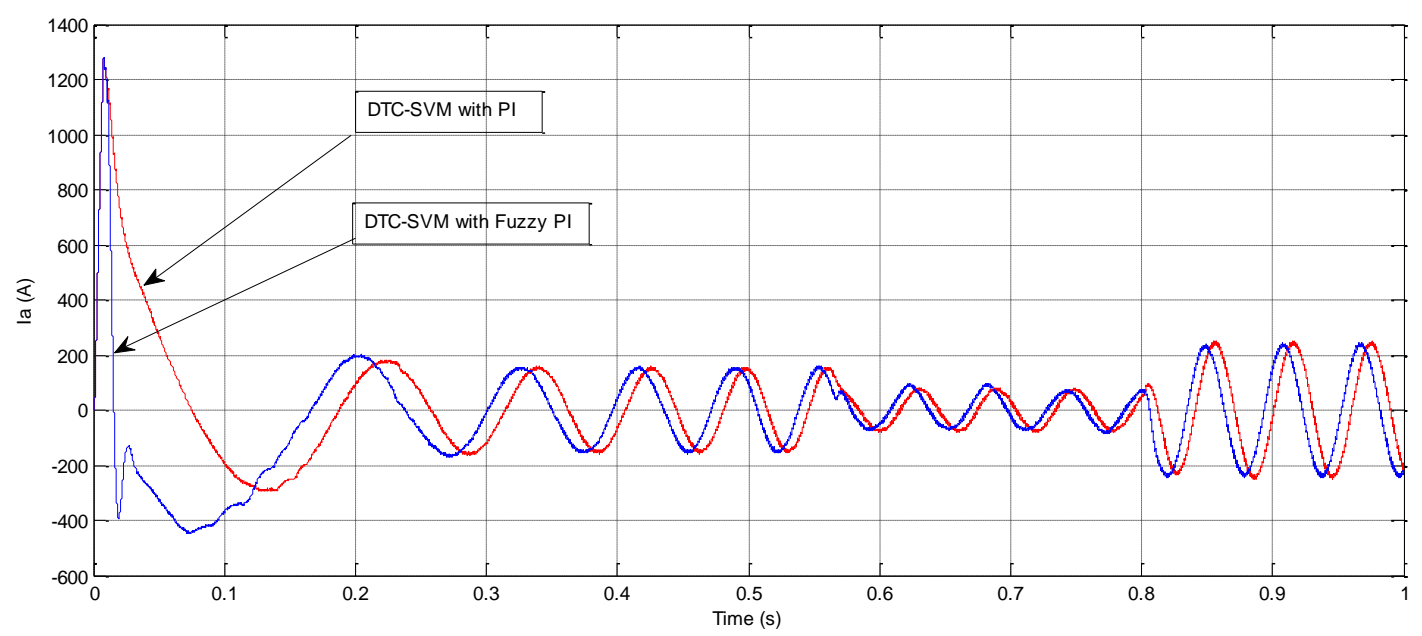

Figure 6. Strator phase-A currents comparison

The comparison of phase-A currents of the stators in the two cases is shown in Fig. 6. The magnitude of stator current fluctuations in the two cases is nearly the same. But the stator current in the second case tends to sinusoidal wave under faster speed. The difference of the stator current is not obvious in steady state in both of the cases.

From the comparisons of the two cases mentioned above, it can be seen that the improved DTC-SVM method with Fuzzy-PI controllers has faster responses at the step changing of speed and electromagnetic torque. And the dynamic and steady state performance of it is better than the DTC-SVM schema with PI controllers. Moreover, the improved DTC-SVM method with Fuzzy-PI controllers has a better speed regulation performance with dynamic load torque.

\section{CONCLUSIONS}

This paper presents an improved DTC-SVM scheme with Fuzzy-PI controllers to control the three-phase induction motors. In this scheme, the speed, electromagnetic torque and stator flux are regulated with Fuzzy-PI controllers. When the error of the variable which needs to be controlled is relatively big, the corresponding fuzzy logic controller can select a larger value for the proportional gain of the PI controller. This will bring faster response speed for the control system. And when the error of it is relatively small, the fuzzy controller can select a relatively lager value for the integral gain of corresponding PI controller, which can help to eliminate the steady state error. This scheme is used to improve the dynamic performance of the conventional DTC-SVM method.

Simulations with the different operating conditions of the presented DTC-SVM scheme and conventional DTCSVM scheme are carried out. According to the simulation results, the DTC-SVM with Fuzzy-PI controllers produced better performances in terms of response speed, flux regulation and speed regulation with dynamic load.

\section{REFERENCES}

[1] Azcue-Puma J L, Gaziolla H, Sguarezi Filho A J, et al. A modified load angle based DTC-SVM scheme for three-phase induction motors[J]. Przegląd Elektrotechniczny, 2013, 89(9): 309-313.
[2] Reza C, Islam M D, Mekhilef S. A review of reliable and energy efficient direct torque controlled induction motor drives[J]. Renewable and Sustainable Energy Reviews, 2014, 37: 919-932

[3] Kalhoodashti H E, Shahbazian M. Hybrid Speed Control of Induction Motor using PI and Fuzzy Controller[J]. International Journal of Computer Applications, 2011, 30(11): 44-50.

[4] Yousef H A, Wahba M A. Adaptive fuzzy mimo control of induction motors[J]. Expert systems with applications, 2009, 36(3): 4171-4175.

[5] dos Santos T H, Goedtel A, da Silva S A O, et al. Scalar control of an induction motor using a neural sensorless technique[J]. Electric Power Systems Research, 2014, 108: 322-330.

[6] Barambones O, Alkorta P. A robust vector control for induction motor drives with an adaptive sliding-mode control law[J]. Journal of the Franklin Institute, 2011, 348(2): 300-314

[7] Lyshevski S E. Control of high performance induction motors: theory and practice[J]. Energy conversion and management, 2001, 42(7): 877-898.

[8] Pucci M. Direct field oriented control of linear induction motors[J]. Electric Power Systems Research, 2012, 89: 11-22.

[9] Gastaldini C C, Vieira R P, Azzolin R Z, et al. An adaptive feedback linearization control for induction motor[C]//Electrical Machines (ICEM), 2010 XIX International Conference on. IEEE, 2010: 1-6.

[10] Ramírez-Leyva F H, Peralta-Sánchez E, Vásquez-Sanjuan J J, et al Passivity-Based Speed Control for Permanent Magnet Motors[J]. Procedia Technology, 2013, 7: 215-222.

[11] Hassan A A, Shehata E G. High performance direct torque control schemes for an IPMSM drive[J]. Electric Power Systems Research, 2012, 89: 171-182.

[12] Ouarda A, Ben Salem F. Induction machine DTC-SVM: A comparison between two approaches[C]//Systems, Signals \& Devices (SSD), 2013 10th International Multi-Conference on. IEEE, 2013: 1-7.

[13] Lazim M T, Al-khishali M J M, Al-Shawi A I. Space vector modulation direct torque speed control of induction motor[J]. Procedia Computer Science, 2011, 5: 505-512.

[14] Pimkumwong N, Onkrong A, Sapaklom T. Modeling and simulation of direct torque control induction motor drives via constant volt/hertz technique[J]. Procedia Engineering, 2012, 31: 1211-1216.

[15] Yousef H A, Wahba M A. Adaptive fuzzy mimo control of induction motors[J]. Expert systems with applications, 2009, 36(3): 4171-4175.

[16] Castillo O, Melin P. A review on interval type-2 fuzzy logic applications in intelligent control[J]. Information Sciences, 2014, 279: 615-631. 
[17] Vukadinovic D, Basic M, Kulisic L. Stator resistance identification based on neural and fuzzy logic principles in an induction motor drive[J]. Neurocomputing, 2010, 73(4): 602-612.

[18] Liaw C M, Wang J B. Design and implementation of a fuzzy controller for a high performance induction motor drive[J]. Systems, Man and Cybernetics, IEEE Transactions on, 1991, 21(4): 921-929.

[19] Sousa G C D, Bose B K, Cleland J G. Fuzzy logic based on-line efficiency optimization control of an indirect vector-controlled induction motor drive[J]. Industrial Electronics, IEEE Transactions on, 1995, 42(2): 192-198.

[20] Hossain A, Singh R, Choudhury I A, et al. Energy efficient wind turbine system based on fuzzy control approach[J]. Procedia Engineering, 2013, 56: 637-642.

[21] Rafa S, Larabi A, Barazane L, et al. Implementation of a new fuzzy vector control of induction motor[J]. ISA transactions, 2014, 53(3): 744-754. 